\title{
Vascular risk factors in glaucoma: the results of a national survey
}

\author{
Nicola Orzalesi • Luca Rossetti • Stefano Omboni • \\ on behalf of the OPTIME Study Group (Osservatorio \\ sulla Patologia glaucomatosa, Indagine Medico \\ Epidemiologica), CONPROSO (Collegio Nazionale dei \\ Professori Ordinari di Scienze Oftalmologiche)
}

Received: 17 July 2006 /Revised: 12 September 2006 / Accepted: 12 September 2006 / Published online: 22 November 2006

(C) Springer-Verlag 2006

\begin{abstract}
Background The role of vascular risk factors in glaucoma is still being debated. To assess the importance of vascular risk factors in patients with primary open-angle glaucoma (POAG), data from the medical history of 2,879 POAG patients and 973 age-matched controls were collected and analyzed.

Methods Design: observational survey. Setting: 35 Italian academic centers. Study population: POAG patients and age-matched controls. In order to reduce bias consecutive patients were included. Observation procedures: data concerning vascular risk factors were collected for all patients with a detailed questionnaire. A complete ophthalmological examination with assessment of intraocular pressure (IOP), visual field, optic disc, and systemic blood pressure was performed. Main outcome measures: the ESHESC (European Society of Hypertension-European Society of Cardiology) guidelines were used to calculate the level of cardiovascular risk. Crude and adjusted estimates of the odds ratios (OR) were calculated for all cardiovascular risk factors in POAG and controls.

Results The study included 2,879 POAG patients and 973 controls. POAG cases had a significantly higher systolic and diastolic blood pressure $(p=0.001)$ and systolic
\end{abstract}

The study was supported by an unrestricted grant from MSD.

No proprietary interest.

N. Orzalesi $(\bowtie) \cdot$ L. Rossetti

Department of Medicine, Surgery and Odontology,

University of Milan, San Paolo Hospital,

Milan, Italy

e-mail: nicola.orzalesi@unimi.it

S. Omboni

Docleader Srl,

Somma Lombardo (VA), Italy perfusion pressure $(p=0.02)$ as compared with controls. Also mean IOP was significantly higher in the POAG group ( $p=0.01$ ), while diastolic perfusion pressure was not significantly different in the two groups. Myopia was more prevalent in the POAG group ( 23 vs $18 \%, p=0.005$ ) as well as a positive family history for glaucoma (26 vs $12 \%, p=$ $0.004)$. POAG patients tended to have a higher cardiovascular risk than controls: $63 \%$ of glaucoma cases vs $55 \%$ of controls (OR: $1.38, p=0.005)$ had a "high" or "very high" cardiovascular risk.

Conclusions The level of cardiovascular risk was significantly higher in glaucoma patients than in controls.

Keywords Glaucoma $\cdot$ Risk factors · Survey

\section{Introduction}

Primary open-angle glaucoma (POAG) is an optic neuropathy that is associated in most cases with elevated intraocular pressure (IOP). Although a number of risk factors, including elevated IOP, have been described, the pathogenesis leading to POAG still remains poorly understood [17].

In the past, two theories were proposed: the mechanical theory in which elevated IOP directly damages the lamina cribrosa and the neural axons [52], and the vascular theory in which the optic neuropathy would be a consequence of insufficient blood supply due to either increased IOP or other risk factors reducing ocular blood flow $[12,17]$. The two theories may not be mutually exclusive and may probably interplay in the same patients. There is today convincing evidence supporting the mechanical theory and the fundamental role of elevated IOP in glaucoma [7, 11, $17,25,27,29,42-44,46]$, although there are conditions, such as the low-tension glaucomas, that cannot be 
satisfactorily explained by the mechanical theory alone [4, $13,17,32,37,45,49]$. The importance of vascular factors is still being debated and several reviews have summarized the evidence about the impact of ocular blood flow in glaucoma [6, 8, 17, 20].

A reduced ocular perfusion in POAG patients compared with normal subjects was reported in a number of studies, including large epidemiologic surveys [3, 31, 47]. The main cause of this reduction would not seem to be atherosclerosis, but rather a vascular dysregulation, leading to both low perfusion pressure and insufficient autoregulation [17]. Several vascular risk factors have been described including atherosclerosis [3, 14, 18, 28, 51], systemic hypotension [19, 23, 26, 40], reduced perfusion pressure [3, 31, 47], vasospastic syndromes (primary and secondary) $[15,16,38,39]$, etc., and their possible role in glaucomatous optic neuropathy has been hypothesized.

The importance of vascular risk factors has often been assessed in the context of population studies which, although including thousands of subjects [3, 31, 47, 51], were actually evaluating only a few glaucomatous patients. In order to assess the importance of vascular risk factors, a national survey of 2,879 POAG patients and 973 agematched controls was conducted in 35 academic centers in Italy (Appendix).

\section{Materials and methods}

Study population The study included 3,972 outpatients aged 50 years or more of both genders. Of these, 2,944 had POAG, while 1,028 served as controls. Written informed consent was obtained from all patients prior to their inclusion into the study. The study was approved by the local Ethics Committees of the centers involved and conducted in accordance with the Declaration of Helsinki.

POAG was defined as: (a) presence of a glaucomatous optic disc (i.e., the vertical cup/disc ratio $\geq 0.7$, or the presence of a "notch" of the optic nerve head rim; consensus of at least two glaucoma specialists was needed for diagnosis of a glaucomatous disc); (b) presence of glaucomatous visual field changes (as tested with the Humphrey 24.2 program), on the basis of abnormal glaucoma hemifield test and corrected pattern standard deviation $(p<0.05)$; and (c) open angle (grades 2-4, Shaffer's classification). Our definition of POAG did not consider IOP levels, which were, in most cases, within the normal range under medical therapy.

Controls were selected among subjects attending the outpatients clinic and having an $\mathrm{IOP}<21 \mathrm{mmHg}$ (i.e., measured on two consecutive occasions separated by an interval of at least $2 \mathrm{~h}$ but not more than 12 weeks), a normal optic disc, and a normal visual field.
Main exclusion criteria were (1) the condition of ocular hypertension (IOP $>21 \mathrm{mmHg}$ ) without glaucomatous optic disc and visual field changes, (2) any previous eye surgery or laser therapy, (3) ocular abnormalities preventing good assessment of IOP, (4) closed-narrow angle (grades 0-1, Shaffer's classification), and (5) proliferating diabetic retinopathy.

In order to reduce potential bias, all cases and controls were consecutive patients. Glaucoma patients and controls were matched (3:1) for age categories (50-55, 56-60, 61-65, etc.).

Study design This was a multicenter (35 academic centers in Italy) observational study. At inclusion medical history was obtained, by trained personnel, from each patient with particular attention to assessment of (cardio)vascular risk factors. This was done through a detailed questionnaire including evaluation of life habits, smoking, drinking, presence of concomitant signs and symptoms or diseases, concomitant drugs, etc. (a translated copy of the questionnaire is available on request). Blood pressure evaluation and a complete ophthalmic examination including a visual field assessment and an IOP diurnal curve were carried out. Office blood pressure was measured with a mercury sphygmomanometer three times at 1-min interval after $5 \mathrm{~min}$ of rest in the sitting position. Auscultatory systolic and diastolic values were taken at the time of the 1 st and 5 th Korotkoff sound, respectively. The average of the three serial measurements was considered for the analysis.

Measurement of IOP was done by means of the Goldmann applanation tonometer at the slit-lamp. The average of three consecutive measurements was considered as the reference value for IOP in the diurnal curve. The mean of five tonometric readings (8 A.M., 11 A.M., 2 A.M., 5 A.M., and 8 A.M.) was considered for analysis purposes.

Analysis Only subjects with a complete questionnaire were included in the analysis.

Since previous studies with a similar design were lacking, no sample size estimation was feasible. However, based on prevalence of POAG in previous population studies [3, 31, 47], it was planned to study about 3,000 patients with glaucoma and 1,000 controls: the number of subjects recruited $(3,792)$ amounted to $99.3 \%$ of planned total.

The questionnaire included a number of questions addressed to the glaucoma specialists of the academic centers involved in the study. In particular, the level of the field damage and the eventual progression of the disease were carefully investigated. Patients with POAG were classified into two different subgroups prior to the study inclusion: one with severe glaucoma (i.e., patients taking three or more drugs, with severe changes of visual field and optic disc, i.e., $\mathrm{MD}<-12 \mathrm{~dB}, \mathrm{C} / \mathrm{D}$ ratio $>0.8$ ) and one with mild to moderate glaucoma (all other cases). 
Continuous variables were summarized by computing group average, median, standard deviation, and minimum and maximum or $95 \%$ confidence intervals (CI), while categorical variables were expressed as absolute and relative frequencies (percentages). Among-groups comparisons of office systolic and diastolic blood pressure, average IOP, as well as systolic and diastolic perfusion pressure (computed as office systolic or diastolic blood pressure minus IOP) were made by analysis of variance. In cases of office systolic and diastolic blood pressure a correction for age, gender, and presence of systemic hypertension was also made, with calculation of adjusted least square means.

Among-groups comparisons of rate of subjects with myopia or family history for POAG was done by the chisquare test with calculation of odds ratio (OR).

Assessment of cardiovascular risk was primarily based on the indications of the recent European Society of Hypertension and European Society of Cardiology Guidelines [10]. The level of office systolic and diastolic blood pressure, the presence of cardiovascular risk factors (age $>55$ years for men, age $>65$ years for women, smoking, alcohol intake, poor or null physical activity, dyslipidemia, family history for cardiovascular diseases), target organ damage, diabetes mellitus, and associated clinical conditions such as cerebrovascular, heart, or peripheral vascular diseases were used for this purpose. Cardiovascular risk was expressed in terms of 10 -year probability of developing cardiovascular diseases and by identifying five levels of risk: average, low (probability $<15 \%$ ), moderate $(15-20 \%)$, high $(20-30 \%)$, and very high added ( $>30 \%)$ risk. For all analyses a $p \leq 0.05$ was used as the level for statistical significance. All analyses were performed with SAS (version 7 for Windows, SAS Institute Inc., Cary, NC, USA).

\section{Results}

Patients' demographics, clinical data, risk factors for glaucoma and cardiovascular diseases Of the 3,972 enrolled subjects, $97 \%$ were included in the analysis: 2,879 with POAG and 973 controls. Data about 65 POAG patients and 55 controls were not sufficiently complete to be included in the analysis. The demographics, clinical characteristics, and distribution of risk factors for glaucoma and cardiovascular diseases of POAG patients and controls are reported in Table 1. Patients with POAG were slightly, but not significantly older than controls. Females were slightly more prevalent in the control group. Patients with severe glaucoma represented $45 \%$ of the whole sample of POAG patients. Main demographics and clinical data of these two subgroups of glaucomatous patients are shown in Table 2.
Table 1 Demographics and clinical characteristics of controls and POAG patients

\begin{tabular}{|c|c|c|}
\hline & $\begin{array}{l}\text { Controls } \\
(n=973)\end{array}$ & $\begin{array}{l}\text { POAG } \\
(n=2,879)\end{array}$ \\
\hline Age (years, mean \pm sd) & $65 \pm 10$ & $68 \pm 9$ \\
\hline Gender (males/females, \%) & $39 / 61$ & $45 / 55$ \\
\hline Smoking $(\%)$ & 15 & 12 \\
\hline Coffee or tea intake $(\%)$ & 86 & 84 \\
\hline Alcohol intake $(\%)$ & 61 & 61 \\
\hline \multicolumn{3}{|l|}{ Diseases and symptoms (\%) } \\
\hline Hypertension & 46 & 48 \\
\hline Dyslipidemia & 30 & 30 \\
\hline Diabetes & 13 & 14 \\
\hline Angina pectoris & 6 & 7 \\
\hline Myocardial infarction & 5 & 4 \\
\hline Heart disease & 8 & 11 \\
\hline TIA & 2 & 3 \\
\hline Cerebral ischemia & 3 & 3 \\
\hline Paralysis or paresis & 2 & 3 \\
\hline Carotid artery stenosis & 5 & 7 \\
\hline Claudicatio intermittens & 4 & 7 \\
\hline Myopia & 18 & 23 \\
\hline Thyroid dysfunction & 11 & 10 \\
\hline Hearing impairment & 4 & 8 \\
\hline Tinnitus & 18 & 22 \\
\hline Headache & 15 & 14 \\
\hline Migraine & 5 & 4 \\
\hline Surgical (vascular) interventions (\%) & 6 & 5 \\
\hline \multicolumn{3}{|l|}{ Concomitant treatments $(\%)$} \\
\hline Hypertensive drugs & 43 & 45 \\
\hline Lipid-lowering drugs & 12 & 12 \\
\hline Antidiabetic drugs & 10 & 12 \\
\hline Reduced physical activity (\%) & 67 & 72 \\
\hline Menopausal status (\%) & 93 & 96 \\
\hline \multicolumn{3}{|l|}{ Family history of (\%) } \\
\hline Myopia & 12 & 12 \\
\hline POAG & 12 & 26 \\
\hline Other types of glaucoma & 1 & 2 \\
\hline Other eye diseases & 12 & 10 \\
\hline Coronary heart disease & 34 & 30 \\
\hline Cerebrovascular disease & 23 & 20 \\
\hline Sudden death & 16 & 13 \\
\hline Hypertension & 51 & 44 \\
\hline Diabetes & 33 & 31 \\
\hline Migraine & 15 & 13 \\
\hline
\end{tabular}

Myopia was significantly more prevalent in the group of patients with POAG (23 vs $18 \%$, OR: $1.46,95 \%$ CI: $1.21-1.76$, $p=0.005$ ). Also diabetes, systemic hypertension, cardiovascular diseases, and to a slightly greater extent hearing impairment and tinnitus, occurred more frequently in POAG, but the difference vs controls was not statistically significant (Table 1). A positive family history for POAG was more frequently reported by glaucomatous patients (26 vs $12 \%$, OR:2.81, 95\% CI: $2.17-3.65, p=0.004)$, while the opposite was true for family history of hypertension (Table 1). 
Table 2 Demographics and clinical characteristics of POAG patients. $C A I$ carbonic anhydrase inhibitors

\begin{tabular}{llll}
\hline & All POAG & $\begin{array}{l}\text { Mild-mod. } \\
\text { POAG } \\
(n=1,591)\end{array}$ & $\begin{array}{l}\text { Severe } \\
\text { POAG } \\
(n=1,288)\end{array}$ \\
& $(n=2,879)$ & $70 \pm 9$ \\
\hline Age (years, mean \pm sd) & $68 \pm 9$ & $66 \pm 9$ & $50 / 50$ \\
Gender (males/females, \%) & $45 / 55$ & $41 / 59$ & $8 \pm 7$ \\
$\begin{array}{l}\text { Duration of glaucoma (years, } \\
\text { mean } \pm \text { sd) }\end{array}$ & $7 \pm 6$ & $6 \pm 6$ & \\
POAG progression in the last & 32 & 17 & 50 \\
5 years (\%) & & & \\
Types of antiglaucomatous & & & \\
treatment & 9 & 6 & 12 \\
Alpha 2 agonists & 70 & 68 & 73 \\
Beta-blockers & 5 & 2 & 9 \\
Systemic CAIs & 27 & 15 & 41 \\
Topical CAIs & 4 & 2 & 7 \\
Parasympathomimetic drugs & 40 & 38 & 66 \\
Prostaglandin analogues & 50 & 2 & 2 \\
Others & 2 & & \\
\hline
\end{tabular}

For all variables no significant differences were observed between the two subgroups of patients with mild-moderate and severe glaucoma.

Blood pressure, IOP, and perfusion pressure Systolic and diastolic blood pressures were slightly, though significantly, higher in the group of patients with glaucoma (Fig. 1). Mean systolic blood pressures were $139.2 \mathrm{mmHg}$ (95\% CI: 138.4 $139.9 \mathrm{mmHg})$ in POAG patients vs $137.1 \mathrm{mmHg}(95 \% \mathrm{CI}$ : $136.2-138.1 \mathrm{mmHg})$ in controls $(p=0.001)$, while mean diastolic blood pressures were $82.4 \mathrm{mmHg}$ (95\% CI: 82.0 82.8 ) in POAG patients vs $81.5 \mathrm{mmHg}$ (95\% CI: 81.0 $82.1 \mathrm{mmHg})$ in controls $(p=0.001)$. The small magnitude of the between-groups difference for systolic and diastolic blood pressure was evident also after adjustment for confounding variables, i.e., age, gender, history of hypertension, and number of antihypertensive medications used. Mean IOP was also significantly higher in POAG patients than in controls (16.5 and $15.4 \mathrm{mmHg}$, respectively, $p=$ $0.01)$. Mean systolic perfusion pressure was significantly higher in the POAG group than in controls $(122.7 \mathrm{mmHg}, 95 \%$ CI: $121.8-123.7 \mathrm{mmHg}$ in POAG patients vs $121.7 \mathrm{mmHg}$, 95\% CI: $120.5-122.6 \mathrm{mmHg}$ in controls, $p=0.02)$, but not diastolic perfusion pressures $(65.8 \mathrm{mmHg}, 95 \% \mathrm{CI}: 64.9$ $66.7 \mathrm{mmHg}$ in POAG patients vs $66.1 \mathrm{mmHg}, 95 \% \mathrm{CI}$ : 65.4-66.6 $\mathrm{mmHg}$ in controls, n.s.) (Fig. 1). In any case no difference was observed for all these parameters between mild-moderate and severe cases of glaucoma.

Level of cardiovascular risk Patients with POAG showed a higher level of cardiovascular risk as compared with controls (Fig. 2). This was evident in the case of very high added risk: the rate of glaucomatous patients falling in high added or very high added categories was 63 vs $55 \%$ of controls (OR: $1.38,95 \% \mathrm{CI}: 1.20-1.60, p=0.005)$. When just the very high added risk category was considered the OR was $1.73(95 \%$ CI: $1.58-1.88, p=0.001)$. No difference in the level of cardiovascular risk was observed between patients with mild-moderate glaucoma and patients with severe glaucoma.

\section{Discussion}

The main finding of this study is that POAG patients had a significantly greater added risk than controls when added

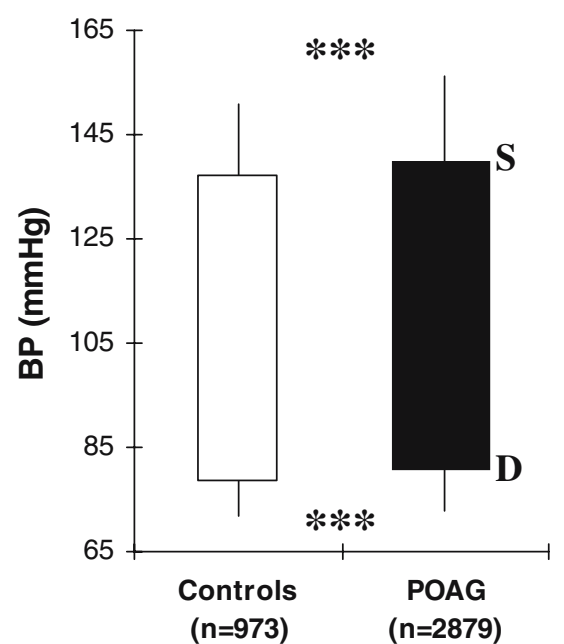

Fig. 1 Mean systolic $(S)$ and diastolic $(D)$ blood pressures $(B P)$, intraocular pressures $(I O P)$, and systolic $(S)$ and diastolic $(D)$ perfusion pressures $(P P)$ in controls (open bars) and in POAG
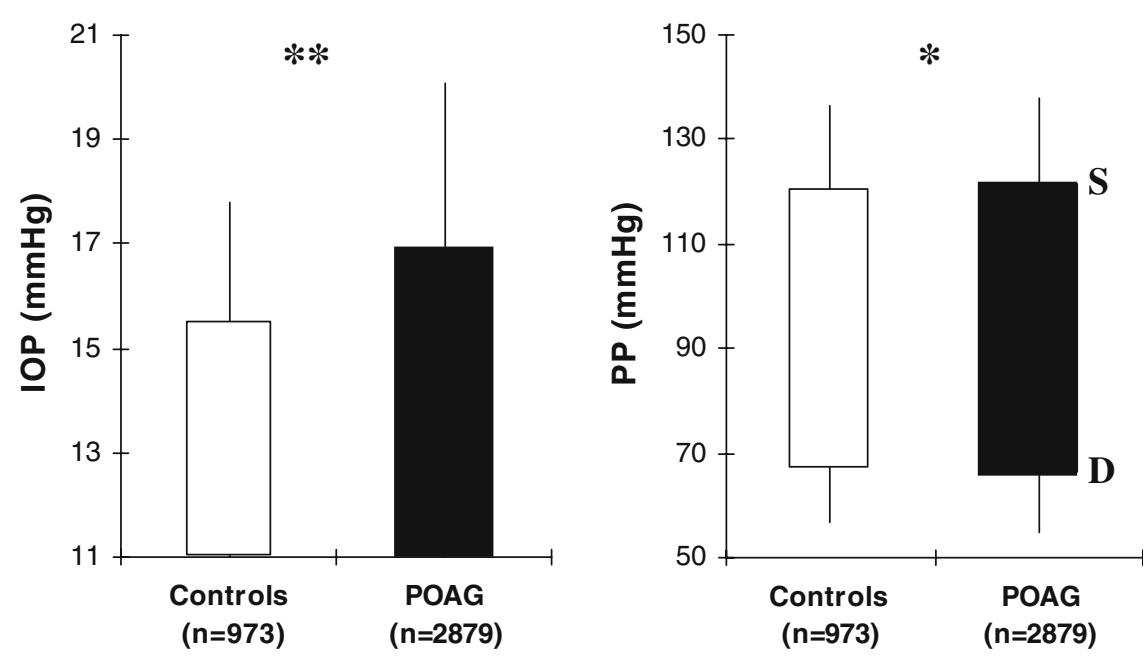

patients (black bars). Asterisks: $* * * p=0.001, * * p=0.01, * p=0.02$ refer to statistically significant between-groups differences 
Fig. 2 Percentages of patients falling in each of the five categories of level of cardiovascular risk. Cardiovascular risk was expressed in terms of 10-year probability of developing cardiovascular diseases and by identifying five levels of risk: average, low (probability $<15 \%)$, moderate $(15-20 \%)$, high $(20-30 \%)$, and very high added $(>30 \%)$ risk. Data are shown separately for controls (open bars) and POAG patients (striped bars)

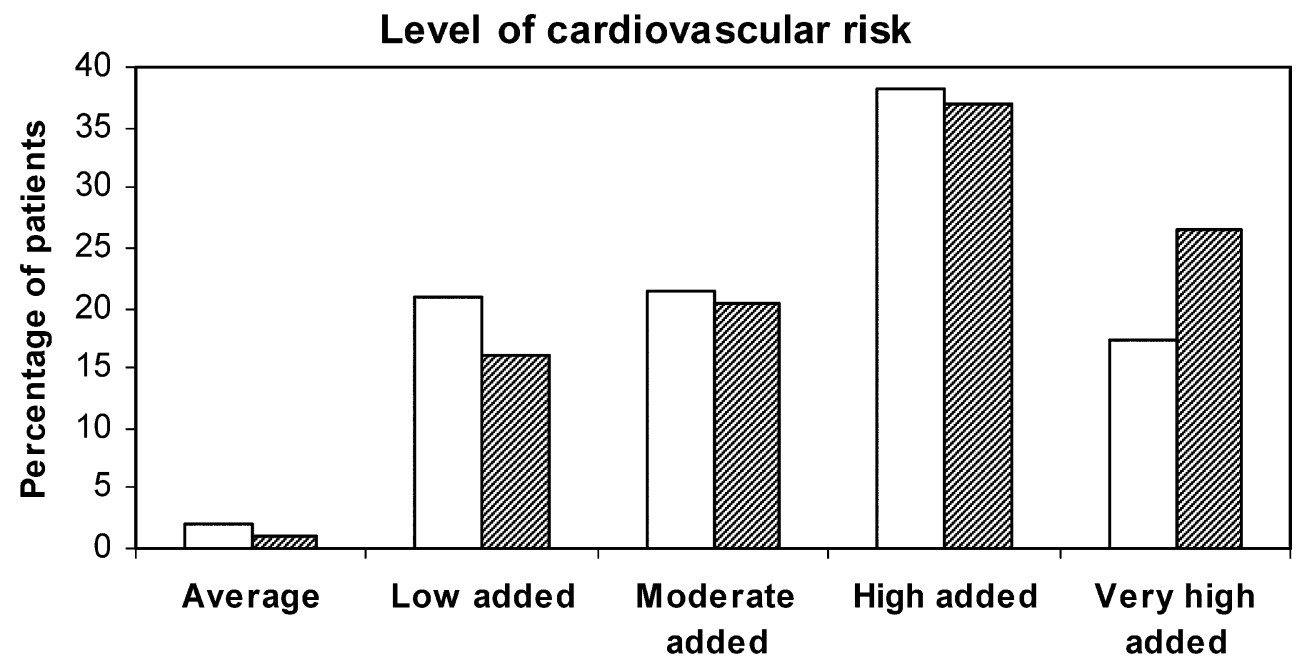

$\square$ Controls $\square$ POAG risk level was very high, i.e., a 10 -year probability of developing a cardiovascular disease $\geq 30 \%$.

Several cardiovascular conditions were more prevalent in the POAG group than in controls. A heart disease was found in $11 \%$ of POAG cases and in $8 \%$ of controls, a carotid stenosis was reported by $7 \%$ of glaucoma patients and by $5 \%$ of controls; a "claudicatio intermittens" was reported by $7 \%$ of POAG patients and by $4 \%$ of controls; a hearing impairment was more than twofold prevalent among glaucoma subjects than among controls (8 vs $4 \%$ ); and finally the condition of "cold limbs" was reported by $24 \%$ of POAG cases and by $21 \%$ of controls. On the other hand, smoking was less frequent in glaucoma patients than in controls, and migraine was not more common among POAG patients. The role played by arteriosclerosis in glaucoma is unclear. Arteriosclerosis was found to be associated with POAG in a number of studies, though a weak relationship was always described [14, 18, 22]. Arteriosclerosis might be associated with an increased IOP [3, 28, 51], and experimental studies suggest that ischemia of the endothelial cells lining Schlemm's canal might lead to IOP elevation [17, 36]; moreover, arteriosclerosis might increase sensitivity of the optic nerve head to elevated IOP [22]. On the other hand, a number of conditions related to arteriosclerosis such as smoking, obesity, hypercholesterolemia, etc. have not been found to be associated with POAG [17].

The higher level of cardiovascular risk in glaucoma might also be explained by the fact that POAG patients showed significantly higher systemic blood pressure values (both systolic and diastolic) than controls. Although the difference in blood pressure levels was really small and of questionable relevance, it reached statistical significance as in other epidemiologic studies. In a recent report of the "Blue Mountains Eye Study" [35], systemic hypertension was found to be modestly, but significantly, associated with an increased risk of POAG, independently of the effect of blood pressure on IOP and other glaucoma risk factors. In particular, systemic hypertension accounted for the greatest attributable risk for POAG than any other POAG risk factors found in the study. Other population studies such as the Rotterdam Study [9] and the Egna-Neumarkt study [3] found a significant association between POAG and hypertension, while in the Baltimore Eye Survey a nonsignificantly increased OR was reported [47] and in the Barbados Study no association was found [31]. There are many possible pathophysiological mechanisms involved in hypertensive damage to the optic nerve [17, 35]: a chronic systemic hypertension might cause microvascular damage with resulting ischemic damage to the anterior optic nerve structures. In addition, systemic hypertension might modify the autoregulation of posterior ciliary perfusion to the optic nerve head, already found impaired in some POAG cases $[21,48]$. Moreover, antihypertensive treatment might determine some dips particularly at night $[19,23]$, which further decrease the amount of blood flow to the optic nerve and consequently result in additional ischemic damage [17, 24, 35].

A higher systolic perfusion pressure was found in glaucomatous as compared with non-glaucomatous subjects. This association was also shown in the Blue Mountains Eye Study [35], in contrast to findings from both the Baltimore Eye Survey [47] and the Barbados Eye Study [31]. On the other hand from our study, POAG patients seemed to have slightly lower diastolic perfusion pressures, though the difference from controls was not 
significant. Besides, the fact that all POAG patients had controlled IOP reduced the chance of finding significant differences from non-glaucomatous cases. The discrepancies reported from the published literature probably arise from the reduced statistical power in the subgroup analyses due to the small number of glaucomatous patients in the population studies [3, 9, 31, 47], but the main confounder remains probably the strong relationship between systemic blood pressure and IOP [35].

The condition of myopia was more prevalent in POAG patients as compared with controls ( 23 vs $18 \%$ ). This finding confirms the results of other papers [33, 41], where myopia was found to be a significant risk factors for POAG [5].

A family history for POAG was reported by $26 \%$ of POAG patients and by $12 \%$ of controls. Although a bias in reporting [34] might help to explain the difference between the two groups, family history is probably an important risk factor for the disease $[1,30,50]$, and one of the strongest in the present study.

Study limitations include the fact that the glaucoma population in this survey might not be representative of the "Italian glaucoma population" and the control group might not be representative of the normal population. As all observational studies, it is open to a number of confounders and bias. POAG patients were consecutive cases treated in academic centers and probably poorly representative of the average glaucoma cases in the population as they receive the best diagnostic assessment, treatment, etc. and do not seem comparable with the POAG patients described in all of the above-mentioned population surveys [3, 28, 31, 47, 51]. In addition, as some results were based on anamnestic findings, further bias might arise from recalling. Controls were selected with the primary feature of not being glaucomatous, in order to study the cardiovascular risk factors in glaucoma. Though the presence of glaucoma could be excluded in these subjects, controls cannot be considered as representative of the population.

Normal-tension glaucomas (NTG) were part of the POAG patients (probably less than half of POAG cases [2]) and were not considered separately as IOP was not an inclusion criteria. As a consequence, the difference between POAG and controls in terms of vascular risk factors might have been diluted by the presence of different types of glaucoma. NTG have been reported to be associated with a number of vascular risk factors, in particular systemic hypotension and vasospasm [17, 19, 23, 24].

In conclusion, POAG patients seem to have an increased cardiovascular risk, in particular when the risk level is high. Though significant, this relationship is weak, as expected and already found in other epidemiologic studies evaluating a small number of glaucoma cases. A higher systemic blood pressure was found in POAG patients and might explain the difference in cardiovascular risk factors from non-glaucomatous cases.
Acknowledgements This study was supported by an unrestricted grant from Merck Sharp\&Dohme.

\section{Appendix}

List of participating centers

University of Bari (Sborgia C, Vetrugno M, Cantatore F), University of Bologna (Campos E, Baldi A), University of Brescia (Quaranta L), University of Cagliari (Serra A, Zucca I, Mura M, Malocci M), University of Catania (Uva M, Longo A, Lombardo A), University of Catanzaro (Scorcia G, Moschettini R), University of Chieti (Gallenga PE, Mastropasqua L, Ciancaglini M, Carpineto P, Lobefalo L), University of Ferrara (Perri P, Paduano B), University of Firenze (Alfieri G, Menchini U, Campana F, Giansanti F), University of Foggia (Delle Noci N, Balducci F), University of Genova (Calabria G, Saccà S, Sanna G, Camicione P, Mastromarino A), University of L'Aquila (Balestrazzi E, Di Staso S), University of Messina (Ferreri G, D'Andrea A), University of Milano San Paolo (Orzalesi N, Rossetti L, Fogagnolo P, Mazzolani F), University of Milano San Raffaele (Brancato R, Carassa R, Bettin P, Fiori M), University of Modena (Guerra R, Martini E, Scarale G, Campi L), University of Napoli (Bonavolontà G, Rinaldi E, Di Meo A, Fusco R), University of Padova (Dorigo MT, Doro D, Grgic V), University of Palermo (Lodato G, Morreale Bubella D, Signorelli F), University of Parma (Gandolfi S), University of Pavia (Trimarchi F, Milano G), University of Perugia (Fiore C, De Carolis A, Sbordone G), University of Pisa (Nardi M, Bartolomei MP, Figus M, Guidi G), University of Roma Policlinico Gemelli (Scullica L, Salgarello T, Colotto A), University of Roma Tor Vergata (Bucci MG, Cerulli L, Manni GL, Centofanti M, Parravano M, Scuderi G, Nucci C), University of Sassari (Carta F, Pinna A), University of Siena (Caporossi A, Frezzotti P), University of Torino (Grignolo F, Brogliatti B, Rolle T), University of Trieste (Ravalico G, Vattovani O, Tritto D, Canziani T), University of Verona (Marchini G, Marraffa M)

\section{References}

1. Bengtsson B, Heijl A (2005) A long-term prospective study of risk factors for glaucomatous visual field loss in patients with ocular hypertension. J Glaucoma 14:135-138

2. Bonomi L, Marchini G, Marraffa M et al (1998) Prevalence of glaucoma and intraocular pressure distribution in a defined population. The Egna-Neumarkt Study. Ophthalmology 105:209-215

3. Bonomi L, Marchini G, Maraffa M et al (2000) Vascular risk factors for primary open angle glaucoma: the Egna-Neumarkt Study. Ophthalmology 107:1287-1293 
4. Chauhan BC, Drance SM (1992) The relationship between intraocular pressure and visual field progression in glaucoma. Graefes Arch Clin Exp Ophthalmol 230:521-526

5. Chihara E, Liu X, Dong J et al (1997) Severe myopia as a risk factor for progressive visual field loss in primary open-angle glaucoma. Ophthalmologica 211:66-71

6. Cioffi GA, Alm A (2001) Measurement of ocular blood flow. J Glaucoma 10(5 Suppl 1):S62-S64

7. Collaborative Normal-Tension Glaucoma Study Group (1998) The effectiveness of intraocular pressure reduction in the treatment of normal-tension glaucoma. Am J Ophthalmol 126:498-505

8. Costa VP, Harris A, Stefansson E, Flammer J, Krieglstein GK et al (2003) The effects of antiglaucoma and systemic medications on ocular blood flow. Prog Retin Eye Res 22:769-805

9. Dielemans I, Vingerling JR, Algra D et al (1995) Primary open-angle glaucoma, intraocular pressure, and systemic blood pressure in the general elderly population. The Rotterdam Study. Ophthalmology 102:54-60

10. European Society of Hypertension-European Society of Cardiology Guidelines Committee (2003) 2003 European Society of Hypertension-European Society of Cardiology guidelines for the management of arterial hypertension. J Hypertens 21:1011-1053

11. Feiner L, Piltz-Seymour JR (2003) Collaborative Initial Glaucoma Treatment Study. Collaborative Initial Glaucoma Treatment Study: a summary of results to date. Curr Opin Ophthalmol 14:106-111

12. Flammer J (1994) The vascular concept in glaucoma. Surv Ophthalmol 38(Suppl):S3-S6

13. Flammer J (1995) To what extent are vascular factors involved in the pathogenesis of glaucoma? In: Kaiser HJ, Flammer J, Hendrickson P (eds) Ocular blood flow: glaucoma meeting. Karger, Basel

14. Flammer J (1997) Vascular risk factors in glaucoma. Klin Monatsbl Augenheilkd 211:5-6

15. Flammer J, Kaiser HJ, Haufschild T (2001) Susac syndrome: a vasospastic disorder? Eur J Ophthalmol 11:175-179

16. Flammer J, Pache M, Resink T (2001) Vasospasm, its role in the pathogenesis of diseases with particular reference to the eye. Prog Retin Eye Res 20:319-349

17. Flammer J, Orgul S, Costa VP, Orzalesi N et al (2002) The impact of ocular blood flow in glaucoma. Prog Retin Eye Res 21:359-393

18. Geijssen HG, Greve EL (1987) The spectrum of primary open angle glaucoma. I: senile sclerotic glaucoma versus high tension glaucoma. Ophthalmic Surg 18:207-213

19. Graham SL, Drance SM (1999) Nocturnal hypotension: role in glaucoma progression. Surv Ophthalmol 43(Suppl 1):S10-S16

20. Grieshaber MC, Flammer J (2005) Blood flow in glaucoma. Curr Opin Ophthalmol 16:79-83

21. Grunwald JE, Riva CE, Stone RA et al (1984) Retinal autoregulation in open-angle glaucoma. Ophthalmology 91:1690-1694

22. Hayreh SS, Bill A, Sperber GO (1994) Effects of high intraocular pressure on the glucose metabolism in the retina and optic nerve in old atherosclerotic monkeys. Graefes Arch Clin Exp Ophthalmol 232:745-752

23. Hayreh SS, Zimmerman MB, Podhajsky P et al (1994) Nocturnal arterial hypotension and its role in optic nerve head and ocular ischemic disorders. Am J Ophthalmol 117:603-624

24. Haireh SS (1999) The role of age and cardiovascular disease in glaucomatous optic neuropathy. Surv Ophthalmol 43(Suppl 1): S27-S42

25. Heijl A, Leske MC, Bengtsson B, for the EMGT group (2002) Reduction of intraocular pressure and glaucoma progression. Results of the Early Manifest Glaucoma Trial. Arch Ophthalmol $120: 1268-1279$

26. Kaiser HJ, Flammer J (1991) Systemic hypotension: a risk factor for glaucomatous damage? Ophthalmologica 203:105-108
27. Kass MA, Heuer DK, Higginbotham EJ, for the OHTS (2002) The Ocular Hypertension Treatment Study: a randomized trial determines that topical ocular medication delays or prevents the onset of primary open-angle glaucoma. Arch Ophthalmol 120:701-713

28. Klein BE, Klein R (1981) Intraocular pressure and cardiovascular risk variables. Arch Ophthalmol 99:837-839

29. Landers J, Goldberg I, Graham SL (2002) Analysis of risk factors that may be associated with progression from ocular hypertension to primary open angle glaucoma. Clin Experiment Ophthalmol 30:235-236

30. Le A, Mukesh BN, McCarty CA, Taylor HR (2003) Risk factors associated with the incidence of open-angle glaucoma: the visual impairment project. Invest Ophthalmol Vis Sci 44:3783-3789

31. Leske MC, Connell AM, Wu SY et al (2002) Risk factors for open-angle glaucoma. The Barbados Eye Study. Arch Ophthalmol 120:954-959

32. Martinez-Bello C, Chauhan BC, Nicolela MT, McCormick TA et al (2000) Intraocular pressure and progression of glaucomatous visual field loss. Am J Ophthalmol 129:302-308

33. Mitchell P, Hourihan F, Sandbach J (1999) The relationship between glaucoma and myopia: The Blue Mountains Eye Study. Ophthalmology 106:2010-2015

34. Mitchell P, Rochtchina E, Lee AJ, Wang JJ (2002) Bias in selfreported family history and relationship to glaucoma: The Blue Mountains Eye Study. Ophthalmic Epidemiol 9:333-345

35. Mitchell P, Lee AJ, Rochtchina E, Wang JJ (2004) Open-angle glaucoma and systemic hypertension. The Blue Mountains Eye Study. J Glaucoma 13:319-326

36. Nakabayashi M (2001) Ischemic hypertension of pigeon eye. Jpn J Ophthalmol 45:128-136

37. Niesel P, Flammer J (1980) Correlations between intraocular pressure, visual field and visual acuity, based on 11 years of observations of treated chronic glaucomas. Int Ophthalmol 3: 31-35

38. Orgul S, Kaiser HJ, Flammer J (1995) Systemic blood pressure and capillary blood-cell velocity in glaucoma patients: a preliminary study. Eur J Ophthalmol 5:88-91

39. Pache M, Krauchi K, Cajochen C et al (2001) Cold feet and prolonged sleep onset latency in vasospastic syndrome. Lancet 358:125-126

40. Perasalo R, Raitta C (1990) Low blood pressure-a risk factor for nerve fibre loss in institutionalized geriatric glaucoma patients. Acta Ophthalmol 68:65-67

41. Perkins ES (1973) The Bedford glaucoma survey. I. Long-term follow-up of borderline cases. Br J Ophthalmol 57:179-185

42. Quigley HA, Addicks EM (1981) Regional differences in the structure of the lamina cribrosa and their reaction to glaucomatous damage. Arch Ophthalmol 99:137-143

43. Sommer A, Tielsch JM, Katz J (1991) Relationship between intraocular pressure and primary open-angle glaucoma among white and black Americans. The Baltimore Eye Survey. Arch Ophthalmol 109:1090-1095

44. Sommer A (1996) Glaucoma: facts and fancies. Eye 10:295-301

45. Stewart WC, Kolker AE, Sharpe ED, Day DG et al (2000) Factors associated with long-term progression or stability in primary open-angle glaucoma. Am J Ophthalmol 130:274-279

46. The AGIS Investigators (2000) The Advanced Glaucoma Intervention Study (AGIS): 7. The relationship between control of IOP and visual field deterioration. Am J Ophthalmol 130:429-440

47. Tielsch JM, Katz J, Sommer A et al (1995) Hypertension, perfusion pressure and primary open-angle glaucoma. A population-based assessment. Arch Ophthalmol 113:216-221

48. Ulrich A, Ulrich C, Barth T et al (1996) Detection of disturbed autoregulation of the peripapillary choroid in primary open angle glaucoma. Ophthalmic Surg Lasers 27:746-757 
49. Weber J, Koll W, Krieglstein GK (1993) Intraocular pressure and visual field decay in chronic glaucoma. Ger J Ophthalmol 2: $165-169$

50. Weih LM, Nanjan M, McCarty CA, Taylor HR (2001) Prevalence and predictors of open-angle glaucoma: results from the visual impairment project. Ophthalmology 108:1966-1972
51. Wu SY, Leske MC (1997) Associations with intraocular pressure in the Barbados Eye Study. Arch Ophthalmol 115: $1572-1576$

52. Yan DB, Coloma FM, Metheetrairut A, Trope GE et al (1994) Deformation of the lamina cribrosa by elevated intraocular pressure. Br J Ophthalmol 78:643-648 